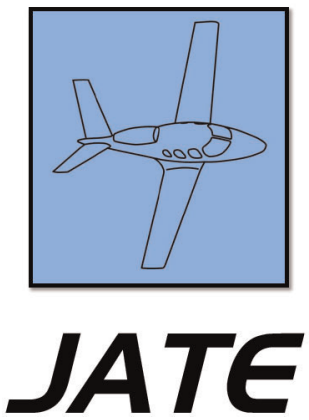

Journal of Aviation Technology and Engineering 9:2 (2020) 12-18

\title{
Tooling Design Modeling for Composite Fuselage of Beechcraft King Air 250 using CATIA
}

\author{
Miazor Fidelis Ekom
}

Changchun University of Science and Technology

\begin{abstract}
Aircraft's constant operation in tough conditions necessitates the need for structural components of high strength yet low weight. Composite materials are being used as an alternative to conventional aluminum alloys because of their competitive strength-to-weight and stiffness-to-weight ratios. In this paper, the detailed design procedure of a light-aircraft composite material fuselage tooling in three dimensions is shown. In its operation, the layup tools provide a surface for the composite part which is the correct shape of the part and is stable through the cure cycle, and also providing a means of indexing the part for the next manufacturing operation. This aims to achieve the desired position accuracy and improve the efficiency of assembly procedures. All the parts are designed and measured using CATIA Version 5 software. The fuselage modeled here is a section of Beechcraft King Air 250. At the time of writing, the manufacturing process for the fabrication of this fuselage is entirely different. This design should be viewed as an alternative process as it would cut down weight and costs while improving safety.
\end{abstract}

Keywords: tooling design, CATIA, composite fuselage, fuselage assembly

\section{Introduction}

In the early years of the aviation era, aircraft flew at lower altitudes and carried lesser loads. There were not many concerns of structural components. However, due to the tough operation conditions and ever-changing forces exerted on aircraft, new low-emission materials which are tougher yet lighter have become a prerequisite. Important developments to address these problems have led to the production of aluminum alloys and then composites which are made up of different sub-materials (Jones, 1998). There are a number of tooling machines which can be used in the fabrication of automated fiber placement (AFP) parts. However, in order to achieve desired position accuracy and increase the efficiency of assembly procedures there is a need to improve the composite layup process (De Backer et al., 2016) for light aircraft beyond the conventional hand layup processes. Abdelal et al. (2015) developed a nonlinear explicit finite element model to simulate the riveting process of a small panel. This focused on the assembly of isotropic metal parts which could not be directly applied to composite parts due to their anisotropic and nonlinear properties (Wen et al., 2019). The objective of this project is not to entirely replace the current manufacturing process of the aforementioned aircraft, but seeks to model an alternative manufacturing process for the fabrication of a light-aircraft composite material fuselage while using a Beechcraft King Air 250 as a case study. The design modelling was created using CATIA Version 5 software. 
The remainder of this paper is organized as follows. Section 2 introduces the terminologies used throughout the text, and also it describes the tooling process. Section 3 presents the structure of the tooling including considerations of various parts of the struts, namely: welded frames, combined frames, dispersed supports, tooling stiffness, and positioning frame. In Section 4, the requirements for tooling design are shown. Section 5 presents extensively the design concept, modeled in CATIA workbench, including the supports, pulley system, electric motor, and AFP tooling head. Section 6 then provides a summary of the work.

\section{Description of the Tooling Process}

In this section, a description of the tooling process, which is referred to as an AFP here, is needed to understand the work presented. First, the basic terminology of the AFP process is defined. Following that, the different functions of the AFP machine are detailed.

\subsection{Terminology}

This subsection is intended for the reader to become familiar with the terms used in this paper.

- Fiber placement. This term refers to composite fabrication processes that involve the laying down of reinforcing fibers along predefined trajectories onto a component (Marsh, 2011).

- Light aircraft. An aircraft that has a takeoff weight that does not exceed 5,670 kg/12,500 lbs. The U.S. term is light plane.

- Fuselage. The main structure or body of a fixed-wing aircraft (FAA, 1st edition).

- Tool. The preform which defines the shape for the layup process. It provides the base geometry for applying consecutive layers (these layers are named plies) of material in order to build up the desired part (called a laminate). The numerical model of this will be used to generate the machine motion numerically and potentially used for simulation of the layup process before real-world usage (Rousseau et al., 2019).

\subsection{Description of the AFP Machine}

The AFP machine is divided into three main parts which have different functions during the AFP process. The first part allows the motion of the machine, the second part is the machine head which handles the layup process (Khan, 2011), and the last part is the tool support. Dirk et al. (2012) extensively describe the different parts of the AFP machine head. The tooling equipment also consists of several subcomponents which include the rotation support connector, motion mechanism, and gantry.

\section{Structure of Tooling}

Welded frames. Welded frames are used for small planar compounds, sections, panels, structures, etc. The standard parts of combined frames are re-usable. They are directly fixed on the ground base with special bolts which are used to join the vertical supports and level beams.

Combined frames. The standard parts of combined frames are re-usable. They are directly fixed on the ground base with special bolts as well. These bolts are used to join the vertical supports and level beams.

Dispersed supports. Dispersed supports have no frames and rely on the workshop ground with application in large assemblies, such as fuselages or wings. They have a lower accuracy.

Single frame base with multiple supports. Have a frame base with adjustable supports; have four optical base points for linearity and eliminate the effect of base variations by the points. The jigs of a single frame base with multiple supports are moveable.

Stiffness of tooling. Checks deflection of beams in the frame, bending moment, and shear force causing deflection. This process is called verification on the stiffness of jig frames.

Stiffness calculation of trusses. Planar trusses using calculation similar to that of beams, spatial trusses using simplified method, finite element methods.

Positioning frame. Frame assembly is to ensure the accuracy and coordination of the premise. The positioning of the assembly should meet the following requirements: shall not have the same orientation on the fixture, mutual interface between the fixture and must be a coordinated process, site selection and reasonable positioning method is reliable, stable positioning pieces are as simple as possible, shall not damage the product when locating the pieces, does not affect the product on the shelf.

\section{Requirements for Tooling Design}

The tooling equipment requires a high degree of durability, directly affecting the accuracy of the aircraft fuselage assembly. Low-quality tools will definitely produce low-quality or substandard parts and it is indeed necessary for the tooling to be got right. Generally, locators of the jig or tooling should have high position accuracy. Factors that affect the position accuracy of locators include: fabrication tolerance of locator, the installation error of locators on the frame, the frame deflection under workloads, improving the efficiency of assembly work, easy operation, using simple jig structures and standard parts, and repeatedly producing assembly within the specified tolerances with little or no distortion. The basic requirements for composite layup tools are slightly different from those of conventional tooling technologies which include: affordability, capability of producing acceptable parts, pass 
dimensional inspections and cosmetic requirements, durability to meet planned production requirements, maintain vacuum integrity, proper reaction to manufacturing loads (that is, autoclave, tape layers, handling, debag/part removal, personnel, etc.), must not introduce contaminants into the process (that is, outgassing, FOD, etc.), and must be safe for layup technicians (no sharp edges, no trip hazards, etc.).

Considerations. Certain factors are taken into consideration as production requirements when designing a composite layup tooling. These factors include: how the tool will be used, processes used, hand layup or automation, autoclave use or oven baked, operation pressure and temperature, and single cure cycle or multiple cycles for bonding multiple details, for co-cure or co-bond.

\section{Design Concept}

This is an AFP machine that uses computer-guided robotics to lay one or several layers of carbon fiber tows onto a mold to create a part. Its working principle is described as continuous rotation of the fuselage while carbon fiber tape is being laid on the fuselage tooling in the direction in which the aircraft will experience certain stresses. For instance, the tape is laid up at an angle of $45^{\circ}$ to the length of the material in the case of torsion, an angle of $0^{\circ}$ or $90^{\circ}$ in the case of tensile and compressive stresses, and so on (Rousseau et al., 2019). This design is based on a study and comparison of the manufacturing processes of the Beechcraft King Air 250. The study and basis of the design were mainly concerning the shape, features, and improvements using CATIA. The measurements and shape of the Beechcraft King Air 250 fuselage were used as reference. Safety was greatly considered in the design of this tooling equipment so as to minimize chances of accidents occurring as has been the case in the past.

\subsection{Shape}

The shape of the tooling equipment expresses CATIA 3D advanced technologies for mechanical surfaces, based on a powerful specification-driven modeling approach. This solution brings high-end-quality surface modeling for any detailed design. In the design of the tooling equipment, the total build is divided into smaller components (parts) or sections for easier compilation and assembly.

\section{Part 1: Fuselage Mount}

Most of the parts of this tooling design were created using sketch-based features in part design workbench. As shown in Figure 1, from left to right as illustrated, the features are: pad, pocket, shaft, groove, hole, rib, slot, etc. The fuselage mount rotates the fuselage plug for composite layup on its surface. This rotation is made possible by means of a system of pulleys and an electric motor which is responsible for the rotation in the pulley system. This pulley

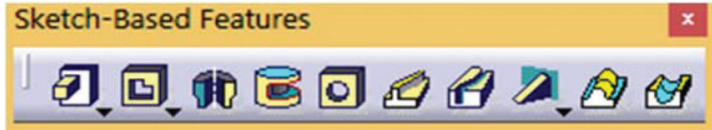

Figure 1. Sketch-based features.

system comprises diving pulley, belt, driven gear, and an electric motor as stated. This part is designed according to the fuselage specification using part design workbench in CATIA. First a circular sketch is formed and then further sketches are made, as shown in Figure 2(a).

The key enabler to the core functionality in the featurebased modeling is learning how to master the sketcher environment. The sketcher workbench provides the ability to create and edit two-dimensional (2D) elements used for creation of three-dimensional (3D) features. The majority of solid features are started by first drawing a 2D profile, known as a sketch. Design intent is then captured by applying parameters and constraints to the geometry.

Multi-pad feature in part design workbench is then used to project already made 2D sketches into $3 \mathrm{D}$ models. This feature enables the $3 \mathrm{D}$ projection of parts. In addition to parts, it also gives the flexibility to control the various sizes of each $2 \mathrm{D}$ section to the desired dimensional projection (Figure 2(b)).

Figure 2(c) illustrates the part of the fuselage mount which serves as locators of the holes on the fuselage bulkhead. These locators ensure correct positioning and locating of the fuselage in the best position.

\section{Part 2: Rotation Supports}

The fuselage mounts are supported by the rotation supports and are connected at their base to prevent relative motion and movement of parts while the composite layup is in process. The rotation supports serve to maintain the weight of the fuselage and to reduce the chances of damage in order to prevent general instability of the whole structure. The rotation supports function as acting panel for the fuselage mount and the fuselage to rest on. They aid in the reduction of concentrated loads. They also serve as a base for the installation of the electric motor responsible for the fuselage rotation. A tough material such as 7075T is selected because of high strength and low fracture toughness (Figure 3).

\section{Part 3: Rotation Support Plane}

This serves as a base on which the fuselage support rests. It prevents relative motion of supports while the machine is working. It is designed using the part design workbench and then using pad feature after being sketched using the sketch design feature. It is shown in Figure 4.

\section{Part 4: Gantry Tracks}

The gantry tracks are paths in which the gantry will continuously translate during working processes. It also bears the load of the various motion units and also the 


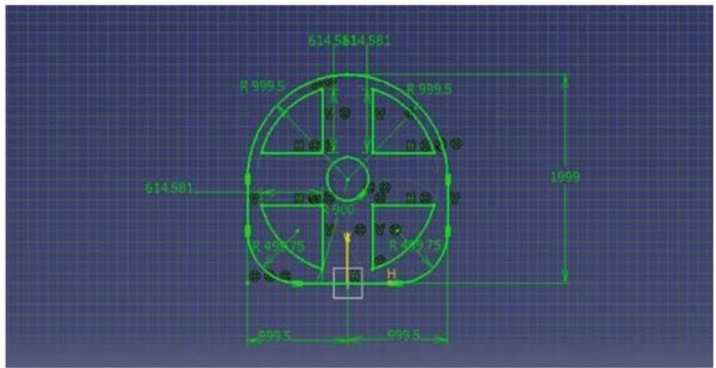

(a)
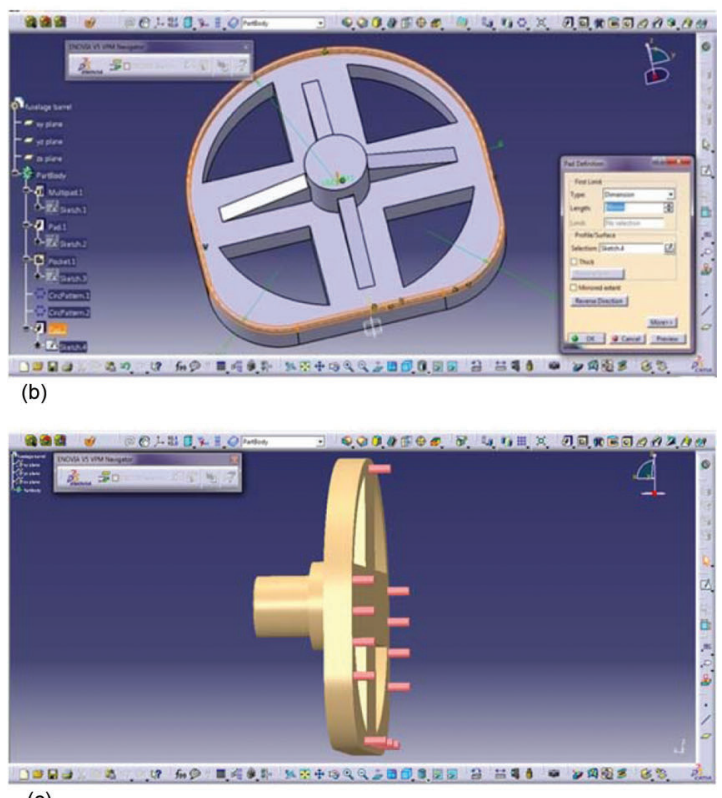

(c)

Figure 2. (a) 2D sketch of fuselage mount. (b) Fuselage mount. (c) 3D fuselage mounts.

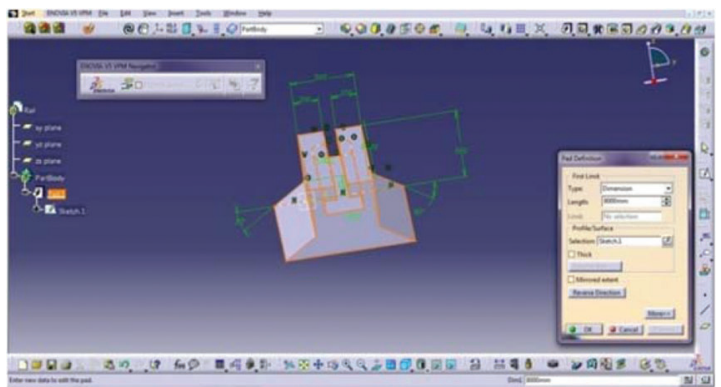

Figure 3. Structure of rotation supports.

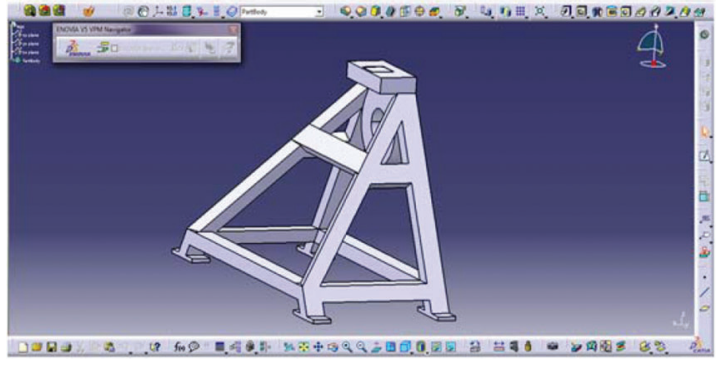

Figure 4. Rotation support plane.

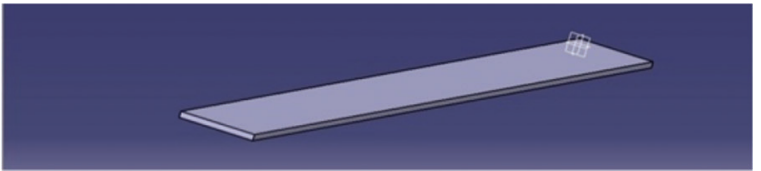

Figure 5. Gantry track.

tooling head (AFP head). The gantry track is shown in Figure 5.

\section{Part 5: AFP Head}

The AFP head handles tow widths of 3.2, 6.4, and 12.7 $\mathrm{mm}(0.125,0.25$, and $0.5 \mathrm{in})$, producing fiber band widths up to $203.3 \mathrm{~mm}$ ( $8 \mathrm{in}$ ). It provides independent control over feed, clamp, cut, and re-start for up to 16 individual tows of composite prepreg slit tape, allowing automated "on-thefly" adjustment of the fiber band width, controlled placement of fibers around changing contours, and precise configuration of openings. The system allows wrinkle-free, near-net-shape layup of enclosed and deeply contoured structures and concave/convex surfaces. It is ideal for precision production of fuselage sections, panels, cowls, ducts, and nozzle cones for commercial, military, and space vehicles, including parts that make use of lightweight honeycomb core materials. The AFP head is shown in Figure 6.

\section{Part 6: Gantry}

The gantry is a submember of the tooling which translates along the gantry track. It is the bearer of the loads from the AFP head and also the vertical motion unit as well as the horizontal motion unit. It is shown in Figure 7.

\section{Part 7: Vertical Motion Unit}

This part is responsible for the vertical translation of the horizontal motion unit and the AFP head along the gantry path or track. It is a slider mechanism attached to the gantry on one end and the horizontal motion unit on the other end. The structure is shown in Figure 8.

\section{Part 8: Horizontal Motion Unit}

The horizontal motion unit consists of a slider mechanism which translated along the track of the vertical motion unit and also travels along the $Z$-axis with the aid of the vertical motion unit being attached on one end. The AFP head is attached to this part, as this part conveys the tooling head to and fro with respect to the fuselage skin surface. It is shown in Figure 9.

\section{Part 9: Fuselage Section Design}

The fuselage is designed from an optimum sketch and projection in geometrical shape design workbench, and then the surface is made using the blend feature (Figure 10(a)). This fuselage is a section of the Beechcraft King Air 250 which is a nine-seat light aircraft. There are reduced numbers of stringers using this fabrication process. 


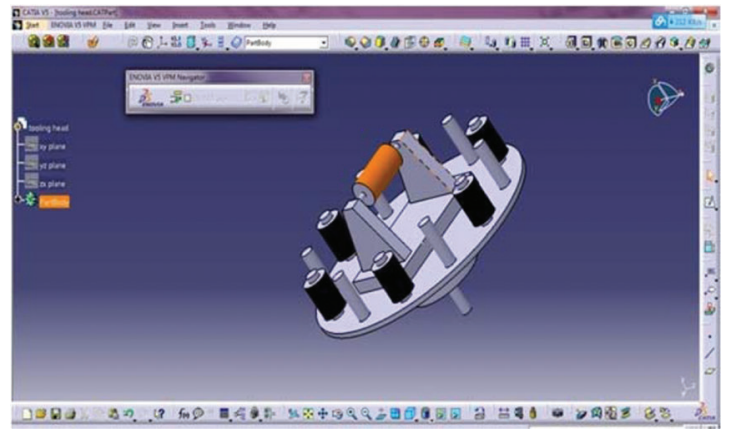

Figure 6. AFP head.

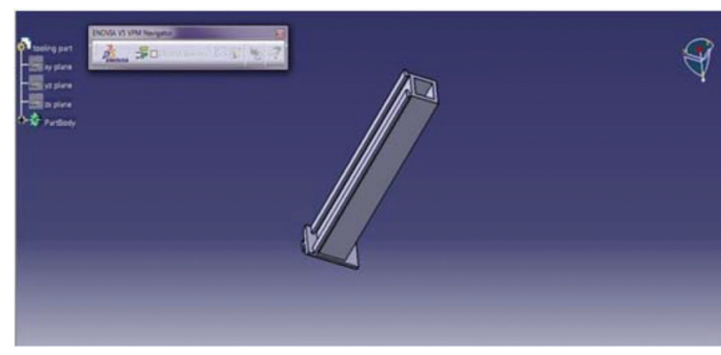

Figure 7. Gantry.

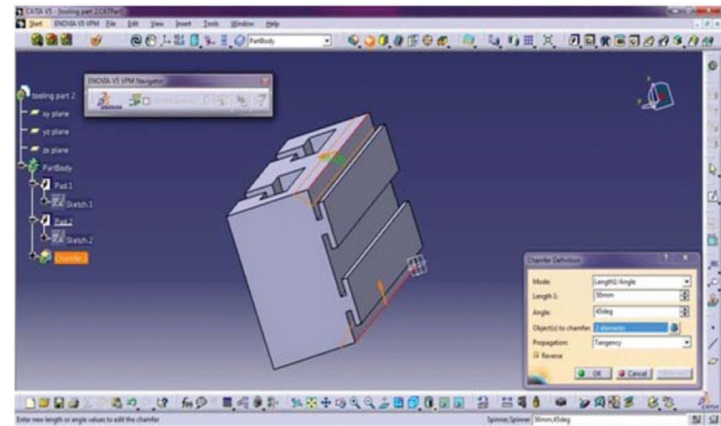

Figure 8. Structure of vertical motion unit.

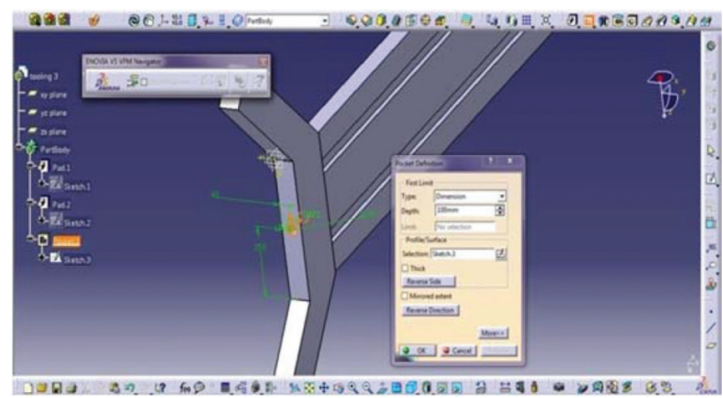

Figure 9. Design of horizontal motion unit.

\section{Part 10: Electric Motor}

The electric motor, shown in Figure 11, generates a rotational motion needed for the pulley system necessary for the rotation of the fuselage section. In this process the AFP head will then layup composites on the fuselage skin.

\section{Part 11: Driving Pulley}

This part is a wheel on the electric motor shaft which is designed to support movement of the timing belt along its

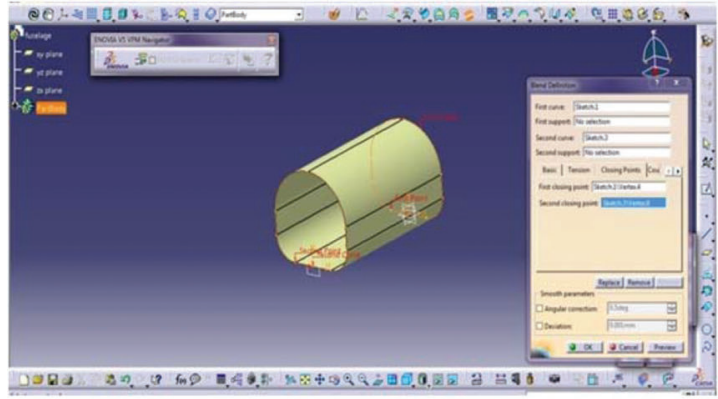

(a)

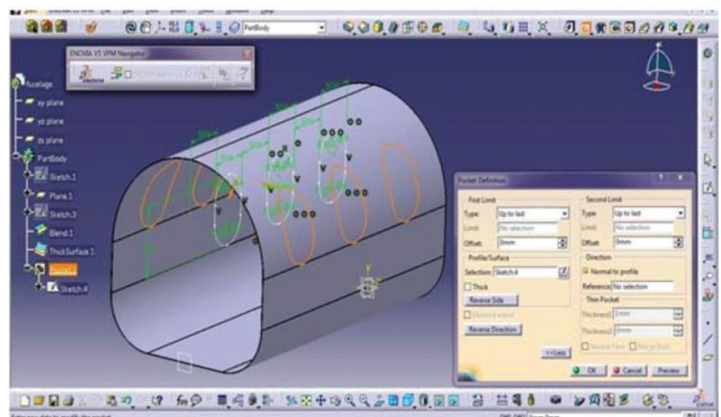

(b)

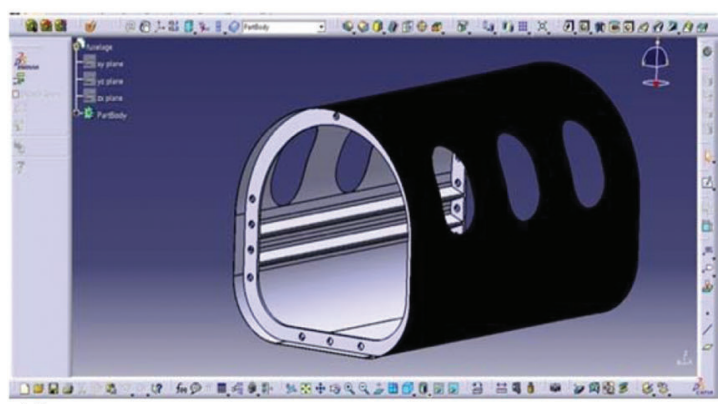

(c)

Figure 10. (a) Fuselage design using blend feature. (b) 3D fuselage (windows). (c) Fuselage with bulkhead and stringers.

direction. It is assembled on the electric motor shaft and transmits the rotational motion to the belt which transmits this motion to the driven pulley. It is shown in Figure 12.

\section{Part 12: Driven Pulley}

The driven pulley transmits the rotational force (torque) and speed to the fuselage mount thereby rotating the fuselage section. It was also designed using the part design workbench in CATIA. A mechanical advantage is realized because the diameter of the driven pulley is larger than that of the driving pulley from the electric motor. It is shown in Figure 13.

\section{Part 13: Timing Belt}

The belt is a loop of flexible material used to mechanically link the two rotation shafts in parallel. It transmits a rotational motion and power efficiency generated from the shaft of the electric motor (driving pulley) to the shaft of the driven pulley connected to the fuselage mount. The belt ensures transmission of reduced rotational speed or timed 


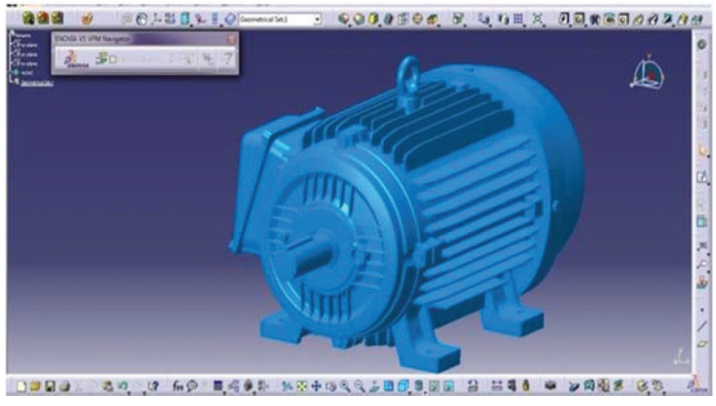

Figure 11. Electric motor.

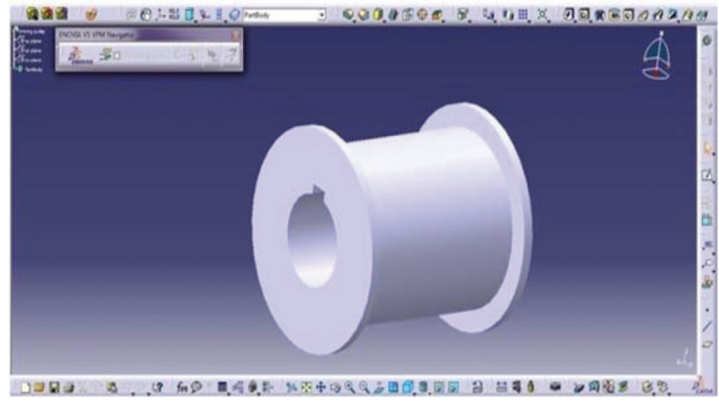

Figure 12. Driving pulley.

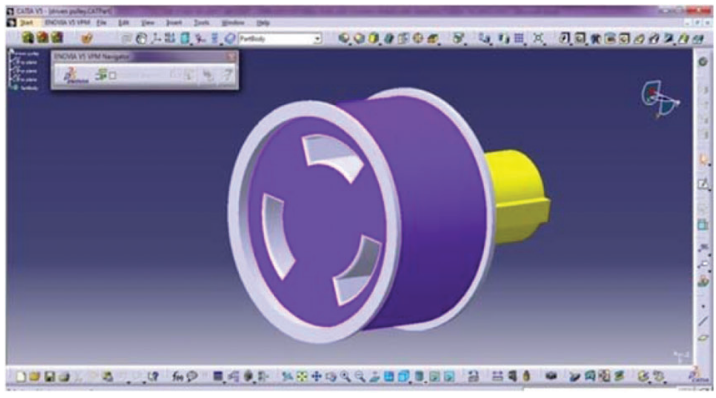

Figure 13. Driven pulley.

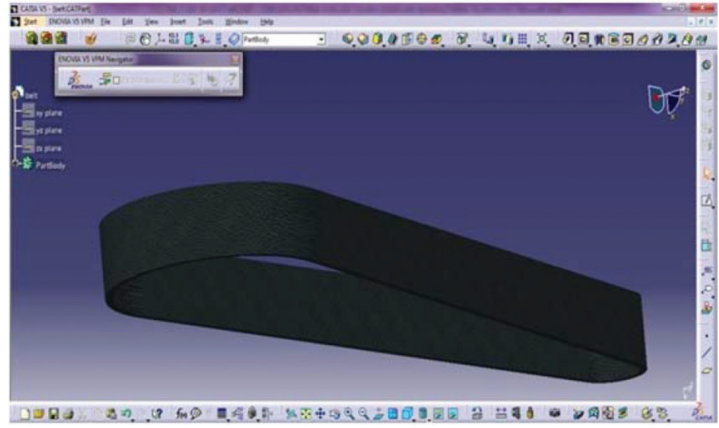

Figure 14. Timing belt.

speed generated from the electric motor. It is shown in Figure 14.

\section{Part 14: Electric Motor Bolt}

The bolt, also designed using part design workbench and pad feature, is a crucial component which is used to fasten the electric motor firmly to the support frame or panel so as

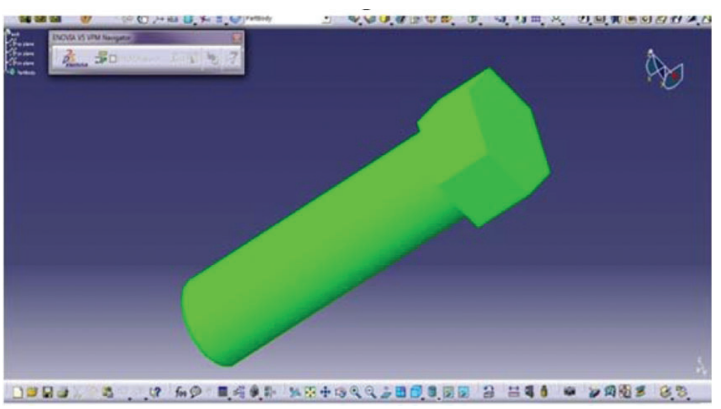

Figure 15. Bolt.

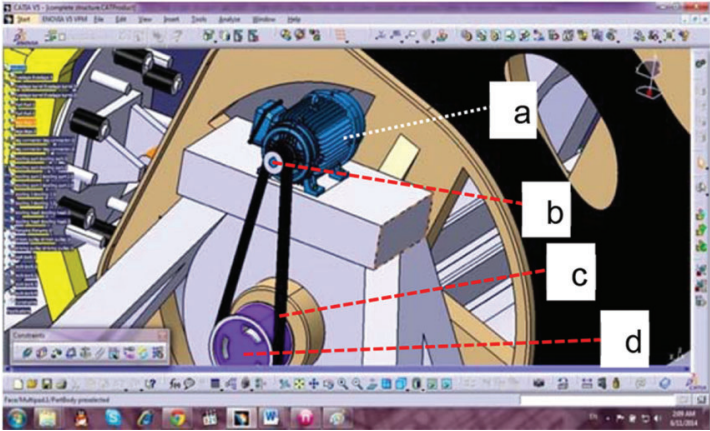

Figure 16. Pulley system.

to prevent the electric motor from disconnection as it may influence the quality of products manufactured. It ensures the stability of the rotation of the complete pulley system. The bolt engages several different types of mechanical forces that can help the resultant joint remain secure. Such forces are clamping force, preloading force, shear force, and tension force. The bolt is shown in Figure 15.

In Figure 16, a pulley system for the tooling is shown. The pulley is driven by an electric motor (a). The timing belt (c) is looped around the driving wheel of the electric motor (b) and that of the driven pulley of the fuselage section (d). When the electric motor is turned on, the powered wheel turns the belt which turns that of the fuselage. While there is rotational motion on the fuselage section, the AFP head which is mounted on the horizontal motion unit lays tows onto the fuselage section.

\section{Final Assembly and Alignment}

After designing all the tools needed to maintain position and location of the part using part design and assembly feature, the final assembly is conducted. This tooling design is an AFP machine as shown in Figure 17. It combines two technologies widely used in industry: automated tape layup (ATL) and filament winding (Khennane, 2013). The AFP process is used to construct large-circumference and complex structures such as fuselage barrels, ducts, and pressure vessels from composite prepreg materials.

ATL utilizes a single, wide, unidirectionally reinforced slit tape to layup simple, gentle contours or flat parts. This is typically the case within automated dynamics as well. 


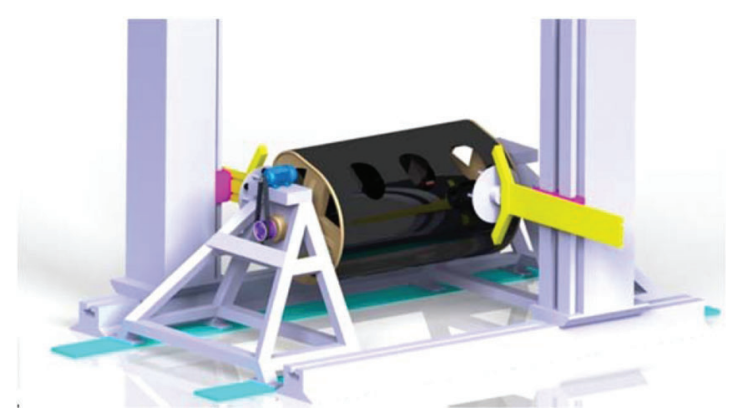

Figure 17. Final 3D assembly of tooling rendered in CATIA.

In its operation, the layup tools provide a surface for the composite part which is the correct shape of the part and is stable through the cure cycle, and also providing a means of indexing the part for the next manufacturing operation.

\section{Summary}

This paper presents the design modelling process of an aircraft composite material fuselage tooling based on CATIA Version 5. This is done in order to achieve desired position accuracy and improve the efficiency of assembly procedures. The light-aircraft fuselage modeled in this paper is a section of a Beechcraft King Air 250. At the time of writing, the manufacturing process for the fabrication of this fuselage is entirely different. This design should be viewed as an alternative process. While the Beechcraft King Air 250 is currently fabricated with aluminum, the work reported here aims to offer some aid in the manufacturing process by presenting a tooling design for a composite-type fuselage section.

\section{Acknowledgments}

This paper and the research involved would not have been possible without the exceptional support of Professor Wang Wei, the Aerospace Dean at Shenyang Aerospace University. Her high-level experience and knowledge have been an inspiration and kept my work on track from my first encounter. Professor Winona Zhang of Changchun University of Science and Technology is thanked for her keen instructions on how I went about my academic paper writing. She is very motivational and a mother like no other. Engineer Jerry Adrian, the Deputy General Manager of Gotiar Aircraft Manufacturing Co. Ltd, is thanked for providing me with an opportunity in his company to learn from the technical engineers. In Gotiar, I was able to experience a real-life manufacturing process of aircraft parts, from the design stage to the final assembly. My colleague Jeremiah Oluwagbemi Abimbola is thanked for his true friendship and endless words of encouragement throughout tough times. I appreciate you, sir. My parents Mr. and Mrs. Fidelis Ekom are thanked for being there at all times and continually supporting my career pursuits. I am truly grateful and cannot but appreciate your love and endless care throughout this project. Petroleum Technology Development Fund (PTDF) of Nigeria is thanked for funding my academic pursuits. I do not only applaud this act of care but also appreciate the sponsorship of this research. I thank God for His grace and for my recovery from an illness that almost claimed my life. The generosity and competence of one and all have improved this study in countless ways and saved me from many errors; those that inevitably remain are entirely my own responsibility.

\section{References}

Abdelal, G. F., Georgiou, G., Cooper, J., Robotham, A., Levers, A., \& Lunt, P. (2015). Numerical and experimental investigation of aircraft panel deformations during riveting process. ASME Journal of Manufacturing Science and Engineering, 137, 011009.

De Backer, W., Kirkpatrick, M., Harik, R., \& Tarbutton, J. (2016). Automated reconstruction of continuous robotic motion from g-code patterns. In Online Proceedings CAD'16, Vancouver, Canada.

Dirk, H. J. A., Ward, C., \& Potter, K. D. (2012). The engineering aspects of automated prepreg layup: History, present and future. Composites Part B: Engineering, 43, 997-1009.

FAA. Aircraft structures. Ebook, 1st Edition.

Jones, R. M. (1998). Mechanics of composite materials. Boca Raton, FL: CRC Press.

Khan, S. (2011). Thermal control system design for automated fiber placement process. Doctoral dissertation, Concordia University.

Khennane, A. (2013). Filament winding processes in the manufacture of advanced fibre-reinforced polymer (FRP) composites. In Advanced fibre-reinforced polymer (FRP) composites for structural applications (pp. 187-206). Woodhead Publishing Series in Civil and Structural Engineering.

Marsh, G. (2011). Automating aerospace composites production with fibre placement. Reinforced Plastics, 55, 32-37.

Rousseau, G., Wehbe, R., Halbritter, J., \& Harik, R. (2019). Automated fiber placement path planning: A state-of-the-art review. ComputerAided Design \& Applications, 16, 172-203.

Wen, Y., Yue, X., Hunt, J. H., \& Shi, J. (2019). Virtual assembly and residual stress analysis for the composite fuselage assembly process. Journal of Manufacturing Systems, 52, 55-62. 